\title{
A Global Insight Into Legalized Abortion
}

\author{
Yanan $\mathrm{Li}^{1, \dagger}$, Linhan $\mathrm{Yi}^{2, \dagger}$, Qingjie Zeng ${ }^{3, \dagger}$, Shiyi Zhang ${ }^{4, *}, \dagger$
}

\author{
${ }^{1}$ University of Alberta \\ ${ }^{2}$ Beijing No.8 high school \\ ${ }^{3}$ Canadian International School of Kunshan \\ ${ }^{4}$ Shanghai Starriver Bilingual School \\ ${ }^{*}$ Corresponding author. Email: Guanghua.ren@gecacademy.cn \\ Those authors contributed equally.
}

\begin{abstract}
With the rise of feminism, many previous policies have been considered unreasonable. The prohibition of abortion is one of them. This matter involves a lot of complicated social cognitions, so there has always been a relatively big controversy. This paper analyzes whether abortion should be legal from the perspectives of women's rights, health, and religious beliefs, and explain the objective advantages and disadvantages of legalized abortion. This study also use practical examples such as South Korea, the United States and other representative countries to analyze the development and rationality of abortion laws in these countries. In the end, the possible solutions that may be implemented at the emergence stage are mentioned.
\end{abstract}

Keywords: Legalized Abortion, USA, Feminism

\section{INTRODUCTION}

\subsection{Historical Context and Development}

Until the end of the nineteenth century, abortion was restricted by laws in imperial countries like UK, Spain and France, the legal restriction then spreading to the whole world through colonialism [1]. From the historical perspective, health issues stemming from abortion were the major concern of strict prohibition. Besides protecting women's lives, restriction on abortion was also associated with religious beliefs and respect for fetal life. Ironically, illegal abortion taken place in an unsafe measure was common worldwide and led to maternal death, failing to protect women's rights and lives at all. According to the estimation of from a Bayesian hierarchical model, there were about 25.1 million unsafe abortions every year based on data from 2010 to 2014 [2]. The situation was even worse in the nineteenth century.

With the medical development and rise of feminism, one of the feminist Alexandra Kollantai pushed the first law reform of legalized abortion in the Soviet Union in 1920 as a great step to take care for women [2]. The realization of providing a safe and legal environment for women to end the pregnancy was sparked, leading to the intense arguments between advocates and opponents towards legal rights of abortion. Till 1936, abortion was prohibited in the Soviet Union again considering population growth. In the worldwide scope, the legalization of abortion has been keeping back and forth, staying unresolved and controversial at the present.

\subsection{Current Problems of legalized abortion}

Women's abortion actually does a lot of harm to themselves, whether physically or psychologically, the pain that women need is painful.

At the physiological level, clinical verification has confirmed that women will increase their chance of infertility by $10 \%$ after the first abortion. It will also increase the mortality rate of premature babies. If the month is too old at the time of abortion, or those who have not been professionally trained to have an illegal abortion, once it causes uterine perforation, hemorrhage, and serious infection will cause life-threatening. Psychologically, it is easy to have a very strong sense of guilt. Although it is only possible, it is still a potential human life. A review of methodologically sound studies of the psychological responses of U.S. women after they obtained legal, nonrestrictive abortions indicates that distress is generally greatest before the abortion [3].

At present, there are also large cultural and religious differences between many regions, and women in some places are restricted by religious beliefs. Some people 
think that a fetus is life, and an abortion is equivalent to killing. This concept occupies the minds of some people with religious beliefs, so if it is really legal, it will cause dissatisfaction among many believers. The "Quran" prescribes: "Foolish people kill their children ignorantly", "Don't kill your own children because you are afraid of poverty", "Killing them is indeed a serious crime." There are also records that explicitly prohibit the act of "killing female infants".

\subsection{The advantages of legalized abortion}

More and more feminist are fighting for the freedom of abortion for women. Women's freedom to obtain an abortion is extremely important to women's freedom. The shackles of women's abortion rights have become a stumbling block that prevents them from being equal with men. When society restricts women by law, it essentially ignores women. In the long run, even if a mother gives birth to a child, she may not be able to raise him. This is a choice that is detrimental to both mother and the child. In addition, the body of women should depend on her own choice, which is a right that a person should have. When women suffer physical pain because they are unable to have an abortion, this essentially undermines women's right to protect themselves.

\section{DIFFERENT ATTITUDES TOWARDS LEGALIZED ABORTION}

\subsection{Agreements: From the Feminism and Women' Rights Perspective}

With the rise of the feminist movement and the gradual emphasis on women's rights, political rights and work can basically guarantee the equal status of men and women in law. However, due to the physiological reasons of women, there have been controversies about whether abortion should be legalized. In fact, if women can't even control their own bodies, they cannot have the same status as men. Access to safe and legal abortion is essential to promoting women's right to health and also to the exercise of control over their life choices [4]. Therefore, many feminist scholars have argued for the liberalization of abortion and have considered this to be a success in terms of feminism or a sign of winning the struggle for a woman's right to choose [5]. Political rights and work can basically guarantee the equal status of men and women in law. Thus, the right to abort was defended on the grounds of a woman's right to individual autonomy [6]. The right to choose the birth of a child and the restriction of the right of a woman as a mother is a denial of human rights. If the law is used to restrict the legality of abortion, this is actually ignoring women, and ignoring women's voice and value. Abortion itself is the choice of respecting the pregnant mother. If interference is imposed, even if the child is born because an abortion cannot be performed, no one will be responsible for the child's life. As stated in the book "The Cider House Rule", whether it is birth delivery or abortion, as long as it helps those helpless women, it is God's work.

Restrictions on abortion will deal a serious impact on women of color and impoverished women. When some women have experienced rape and cannot have an abortion, this essentially destroys women's right to protect their health. They cannot have an abortion and will experience a long period of pain. In the long run, it is a huge harm to women's bodies. In South Africa, when abortions were allowed, the number of women who died of abortions fell by $91 \%$ [7]. This shows that when women have the right to abortion, they will be healthier instead of trying dangerous abortion methods. However, laws such as Alabama, Texas, Kentucky, and Utah have introduced laws that reduce the possibility of abortion. This shows that women in these areas lack safety protection, and the number of these laws is increasing year by year. These prohibitions are inherently unfair to women. The government should not interfere with women's right to decide on abortion. This not only suppresses women but also hinders doctors from helping patients.

Here is a point by Marquis de Sade that he mentioned a woman's body is a woman's own choice [8]. To understand this, sentence some points can be concluded. First, when the mother is pregnant, the baby is completely dependent on the mother, which means that the mother can choose to keep or have an abortion. When everything the child needs must be provided from the mother's body, she will think that the child is completely controlled by her, which also means that the child's survival or death is determined by the mother. When the mother does not want the child, she has the right to destroy the child. For example, Nobel Prize winner Dr. Francis Crick, one of the co-discoverers of DNA, actually claimed that "no newborn infant should be declared human until it has passed certain tests regarding its genetic endowment, and that if it fails these tests, it forfeits the right to live [8]." The second point is the child needs to rely entirely on the mother to provide oxygen and food. The child is like an accessory in the mother's body, and the mother has the right to have an abortion. The third point is to alleviate the mother's guilt, many people imagine the child as a parasite (a harmful substance) in the body. Parasites in the body will suck the nutrients in the body, so it must be removed. All of this mentioned that women and children are separate bodies and separate people which means they may have different blood types and races. When the unborn child anchors to the uterine wall, there is a concerted attack by white blood cells to defeat him, and he must defend himself [8]. Mothers' immune systems will recognize that it is not part of her body. It expresses women should have the right to abortion when they felt the danger the a child will bring them. 
From all these perspectives, abortion is a settled, inviolable right that is central to achieving not only reproductive health goals but women's freedom over their bodies [7]. Women have absolute rights to manage their bodies. When there is no intervention by others, no community intervention, or no government intervention, women's health status will be better.

\subsection{Opposition to Abortion: Intersectional Lens of Religion, Morality and Mental Health}

The controversy about legalized abortion have been increasingly intense after the Roe $V$. Wade decision of 1973. For its interdisciplinary essence, the debate over abortion covers a wide range of topics, including "theology, women's right, civil liberties", triggering emotional responses of citizens [9]. Under the trend of legalizing abortion, opposition to abortion is mostly associated to religion, moral values and women's mental health, considering pro-life theory, respect for religious norms and care for mental health. Relating to education, sex, religious background, race and region, it requires an intersectional lens to research into the anti-abortion advocates for understanding the political topic in depth and complexity.

Specifically, based on the Christian doctrines, sex is forbidden out of marriage and before marriage, regarded as "sinful behavior" [9]. Religious groups consider abortion as a legitimate strategy to handle the outcome of sexual activity, unwanted pregnancy. Even not on the moral grounds, abortion should be prohibited to protect the conservative norms of religiosity [9]. In the religious point of view, according to Jelen, religious preference and religious intensity are both related to opposition to abortion [9]. There is a societal assumption about religion preference: Catholics hold a stronger opposing viewpoint than Protestants because of a Catholic theological idea that "the spirit or soul enters the body at conception" [10]. Catholics are considered as one of the most determined religious group in opposing abortion for its conservative norms. As the study of Westoff shows, the extent of antiabortion is correlated with how traditional and conservative the religious groups are [10]. Secondly, religious intensity, measured by church attendance, also affects the opposition to abortion. According to the data based on a sample of " 325 social worker and 125 nurses", the hypothesis that members of liberal denominations are more likely to approve of abortion is confirmed [11].

On the moral ground, the pro-life Vs pro-choice debate reflects arguments held by advocates and opponents to legalized abortion. Pro-life argument states an advocate for legal protection of fetuses while prochoice argument emphasizes the reproductive rights of women to make their own choices. According to Marquis, abortion is a "seriously immoral" act, similar to kill "an innocent adult human being" [12]. Excluding extreme cases like life-threatening pregnancy or pregnancy after rape, Don Marquis argues that a majority of abortions are immoral by introducing a new lens to define abortion, out of the loop of pro-life and pro-choice. He compares and contrasts pro-choice and pro-life arguments, figuring out that both arguments centering out whether fetuses have the right to life or own the obligation to end life. The discovery of similarities in logic behind both arguments leads Marquis to alternatively deduce his conclusion from a morally consented assumption: "it is wrong to kill $u s$ " [12]. He assumes that killing an adult is wrong because of its negative consequences left on the victimending one's future. The same logic could be applied to abortion because it is a process to end a fetus's future to develop, no matter of whether fetus is a human being.

According to Priscilla K. Coleman's research, women's mental health is directly related to abortion, and unlike other articles, it uses more precise formulas and data to convince the audience, where Coleman states that "women who had undergone an abortion experienced an $81 \%$ increased risk of mental health problems, and nearly $10 \%$ of the incidence of mental health problems was shown to be directly where it is also reported that women who had undergone an abortion experienced an $81 \%$ increased risk of mental health problems, and nearly $10 \%$ of the incidence of mental health problems was shown to be directly attributable to abortion.[13] Women with a history of abortion have a $61 \%$ increased risk of developing mood disorders compared to women with no history of abortion. Abortion can make women more likely to suffer from social phobia and even increase the likelihood of suicide.

In addition to this, the frequency of PTSD (Posttraumatic stress disorder) and antidepressant use can also be evidence that abortion can directly affect a woman's mental health. Although Inger Wallin Lundell's research confirms that only a small percentage of women actually experience PTSD as a result of abortion, most women experience it as a result of experiences unrelated to abortion. However, a small percentage of women do experience PTSD as a result of abortion, which should not be overlooked, and the depression and anxiety associated with abortion are also being taken seriously and are of concern [14]. It is worth noting that because the sequelae of abortion and childbirth are almost identical, comparisons are often made between the two. According to a study by Dr. Julia R. Steinberg, antidepressant medication is used more frequently in the year following a woman's first abortion than in the year following a woman's first birth, so women who have an abortion are more likely to use antidepressants than women who do not have an abortion. Similarly, mental health problems may in turn lead women to have an abortion. Thus, these two are directly related [15]. 


\section{A REVIEW OF LEGALIZED ATION IN DIFFERENT COUNTRIES}

\subsection{Chile}

Recognized as a Catholic-dominant country, Chile was one of the few countries that restricted abortion without any exception. According to Chilean penal code, abortion was against social morality and familial harmony, leading to incarceration about three to five years [16]. Once in 1931, Chile legalized therapeutic abortion to advocate for women's health and reproductive rights but in 1989, abortion was again prohibited by General Augusto Pinochet under all circumstances [16].

The strict law was ineffective in prohibiting abortions and caused severe health issues and even deaths because of secretly carrying out unsafe abortions [17]. The restriction was not only about gender equality but an enlarging gap between rich and poor. Poor women had to withstand the risk of unsafe abortions and being imprisoned, or they would become poorer with kids to nurture [16]. Human rights for those women were devastated under the criminal law about abortion. It was till 2015 President Bachelet took her responsibility to call upon women's equality and reproductive rights with a bill to permit certain circumstances of abortion. With the monitoring of strict medical diagnosis, abortion is legal on three grounds: a life-threatening pregnancy; fetal anomaly; and rape [17]. The bill immediately received intense criticism from opponents including church people and essential medical institutions in Chile due to the opposing attitude of the Chilean Catholic Church.

The social debate over the bill continued for two years and headed in a positive direction. President Bachelet and her followers were determined in advocating women's movement and caring for social justice. Her identity as a doctor before and female leader allowed her to be solid and credible in modifying abortion law. Beside her efforts, media focus on those rapists who led to death of girls because of unsafe abortion led to serious public reflection between the pro-life activist and pro-choice feminists. Through a heated session, the proposal was finally approved in September 2017, marked as a breakthrough for Chile's legalized abortion even thought it was strictly limited to three situations [17].

The future of legalized abortion is still a long journey to pursue in this conservative Roman Catholic country considering the back-and-forth process to legalization.

\subsection{South Korea}

South Korea's criminal law repealed the illegal abortion bill in 2020 [18]. Abortion was once is banned in Korea except for infectious diseases, rape, and sexual violence between relatives. Otherwise, they may face fines or criminal detention. The Constitutional Tribunal believes that it is an excessive violation of women's right of self-determination to completely oppose abortion and allow abortion only within a limited range. Pregnancy and childbirth are important issues that have a fundamental and decisive impact on women's lives. Therefore, the question of whether to continue to conceive is a decision made by women based on their choice of life and social outlook and through careful consideration. At the same time, in order to protect women's right to self-determination, sufficient time should be given to decide whether to continue pregnancy.

Of course, in South Korea's special social environment, South Korea still screens the gender and then decides whether to give birth. Feminism prevails in South Korea, and there are even cases of organized abortion of male fetuses. In some places, there is a patriarchal mentality, so they will have abortions because they are daughters. Governments have sought to address the problem by banning access to the technology of prenatal sex-detection, usually accompanied by banning sex-selective abortion [19]. The impact of this on society is naturally bad. On the whole, liberating women's right to abortion is a kind of relief for women, but it will also cause some bad effects on the country because of culture.

\subsection{USA}

In the United States, a country that strives for democracy and freedom, the legalization of abortion has nevertheless been a highly controversial issue. Since 1973, the US Supreme Court has declared abortion to be legal. Since then, many politicians have been working to overturn this decision, even though according to public opinion polls $73 \%$ of people believe that abortion should be legalized. 2019, some US states have passed laws banning abortion, and other states have been deciding to restrict abortion [20].

However, laws are not the only obstacle to restricting abortion. Medically speaking, there are not enough abortion clinics in the U.S. For example, in Alabama, 93\% of counties do not have abortion clinics, so many people need to travel to other states to get an abortion. [20] According to research, anti-abortion laws have not prevented or reduced abortions, but rather made them dangerous. Because abortions can be safe when they are performed under normal sanitary conditions and with medical staff, when abortions are restricted people are forced to go to small unsafe places to get an abortion. Their safety is not guaranteed. Currently, around 5 million women worldwide are hospitalized each year for abortions and related complications, and around 47,000 women die as a result. [19] It is worth noting that the United States has the highest maternal mortality rate from abortion and related complications of any developed country.

On top of this, low-income people (e.g., refugees, people of color) are more restricted from having an 
abortion because they do not have enough money to pay for one and take time off work. Teenagers are even more likely to need parental consent to have an abortion. According to data, the maternal mortality rate for black (African) Americans in the US is four times higher than that of white Americans.

\section{CONCLUSION}

From the countries mentioned above, we can see that the legal issue of abortion still takes time. The legality here refers more to morality or acceptance by a part of the people, just like Chile. However, in bad circumstances such as physical health or rape, women should have the legal right to abortion. Like South Korea, considering women's health issues, such as infectious diseases and other dangerous diseases, they began to agree with the legality of abortion under certain permitted circumstances. Therefore, it can be seen from a large scale that women's rights are gradually being valued, women's health and safety issues are being paid attention to, and the entire system is developing in a good place.

\section{REFERENCES}

[1] Ganatra, B., Gerdts, C., Rossier, C., Johnson, B. R., Jr, Tunçalp, Ö., Assifi, A., Sedgh, G., Singh, S., Bankole, A., Popinchalk, A., Bearak, J., Kang, Z., \& Alkema, L. (2017). Global, regional, and subregional classification of abortions by safety, 2010-14: estimates from a Bayesian hierarchical model. Lancet (London, England), 390(10110), 2372-2381. 6736(17)31794-4

[2] Berer M. (2017). Abortion Law and Policy Around the World: In Search of Decriminalization. Health and human rights, 19(1), 13-27.

[3] Adler, N. E., David, H. P., Major, B. N., Roth, S. H., Russo, N. F., and Wyatt, G. E. (1990). Psychological responses after abortion.

[4] Sclater, S. D., Ebtehaj, F., Jackson, E.\& Richards, M. (2009). Regulating autonomy: Sex, reproduction and family.Oxford: Hart Publishing.

[5] Eriksson, M. K. (2001). Abortion and reproductive health: Making international law more responsive to women's needs. In K. Askin \& D. Koening (Eds.), Women and international human rights law (pp. 218). New York: Transnational Publisher.

[6] Cook, R., \& Dickens, B. (2003). Human rights dynamics of abortion law reform. Human rights quarterly, 25(1), 1-59.

[7] The Lancet. (2019). We must all support women in the fight for abortion. 393(10186), doi:10.1016/S0140-6736(19)31182-1
[8] Brian, C. (2018). Shouldn't women be able to control their own bodies?

[9] Jelen, T. (1984). Respect for Life, Sexual Morality, and Opposition to Abortion. Review of Religious Research, 25(3), 220-231. doi:10.2307/3511120

[10] Petersen, L., \& Mauss, A. (1976). Religion and the "Right to Life": Correlates of Opposition to Abortion. Sociological Analysis, 7(3), 243-254. doi: $10.2307 / 3710566$

[11] Helen Rose Fuchs Ebaugh, \& Haney, C. (1978). Church Attendance and Attitudes toward Abortion: Differentials in Liberal and Conservative Churches. Journal for the Scientific Study of Religion, 17(4), 407-413. doi:10.2307/1385404

[12] Marquis, D. (1989). Why Abortion is Immoral. The Journal of Philosophy, 86(4), 183-202. doi:10.2307/2026961

[13] Coleman, Priscilla K. "Abortion and Mental Health: Quantitative Synthesis and Analysis of Research Published 1995-2009." British Journal of Psychiatry, vol. 199, no. 3, Sept. 2011, pp. 180-186, www.cambridge.org/core/journals/the-britishjournal-of-psychiatry/article/abortion-and-mentalhealth-quantitative-synthesis-and-analysis-ofresearch-published19952009/E8D556AAE1C1D2F0F8B060B28BEE 6C3D, 10.1192/bjp.bp.110.077230. Accessed 9 Oct. 2021.

[14] Wallin Lundell, Inger, et al. "Posttraumatic Stress among Women after Induced Abortion: A Swedish Multi-Centre Cohort Study." BMC Women's Health, vol. 13, no. 1, Dec. 2013,bmcwomenshealth.biomedcentral.com/article s/10.1186/1472-6874-13-52, 10.1186/1472-687413-52. Accessed 15 Aug. 2021.

[15] Steinberg, Julia R., et al. "Examining the Association of Antidepressant Prescriptions with First Abortion and First Childbirth." JAMA Psychiatry, vol. 75, no. 8, 1 Aug. 2018, p. 828, jamanetwork.com/journals/jamapsychiatry/articleabstract/2681170, 10.1001/jamapsychiatry.2018.0849. Accessed 15 Aug. 2021.

[16] Lu Li. (2015). The War of Legalized Abortion in Chile. Adolescents and Society:(2), 96-97.

[17] Maira, G., Casas, L., \& Vivaldi, L. (2019). Abortion in Chile: The Long Road to Legalization and its Slow Implementation. Health and human rights, 21(2), 121-131.

[18] [Book] Penal Code of South Korea 
[19] Is banning sex-selection the best approach for reducing prenatal discrimination? Das Gupta M Asian Population Study , 15(3):319-336 14 Nov 2019

[20] "10 Things You Need to Know about Abortion Laws in the US." Amnesty International, 11 June 2019,

www.amnesty.org/en/latest/news/2019/06/abortion -laws-in-the-us-10-things-you-need-to-know/.

Accessed 16 Oct. 2021. 